\title{
Seroprevalence of Mycoplasma gallisepticum and Mycoplasma synoviae infection in the commercial layer flocks of the Centernorth of Iran
}

\author{
Payam Haghighi-Khoshkhoo*, Gita Akbariazad, Masood Roohi, Javad Inanlo, Mehran Masoumi and \\ Pedram Sami-Yousefi
}

Department of Clinical Sciences, Karaj Branch, Islamic Azad University, Karaj Branch, Karaj- Iran.

Accepted 1 September, 2011

\begin{abstract}
This survey was carried out to determine the seroprevalence of Mycoplasma gallisepticum (MG) and Mycoplasma synoviae (MS) infections in commercial layer farms in Centernorth of Iran. A total of 2000 serum samples were collected from 40 commercial layer flocks (50 samples/ flock) mostly > 40-weekold. Sera tested by serum plate agglutination (SPA) method using commercial MG antigen and MS antigen. Positive reactions retested by SPA on 1:8 dilution and the flocks with more than $10 \%$ positive reactions considered positive serologically. The results showed that 4 of $40(10 \%)$ flocks were MG positive and the rest (90\%) were negative. About MS, 17 of $40(42.5 \%)$ flocks were positive and 33 of 40 (57.5\%) were negative. Sera tested for MG were: 125 of 2000 (6.25\%) positive, 1821 of 2000 (91.05\%) negative and 54 of $2000(2.7 \%)$ suspect. Sera for MS were: 371 of 2000 (18.55\%) positive, 1617 of 2000 $(80.85 \%)$ negative and 12 of $2000(0.6 \%)$ suspect. Statistical analysis showed a positive correlation between MS positive flocks and strain (LSL flocks compared to Hy-Line flocks) and capacity of the farms significantly $(P<0.05)$. It seems that the seroprevalence of $M S$ in the commercial layer flocks of the Centernorth of Iran is high.
\end{abstract}

Key words: Mycoplasma gallisepticum, Mycoplasma synoviae, seroprevalence, serum plate agglutination test.

\section{INTRODUCTION}

Avian Mycoplasmosis caused mainly by Mycoplasma gallisepticum (MG) and Mycoplasma synoviae (MS), can cause considerable economic losses in chicken such as chronic respiratory disease, reduce weight gain and meat quality and increase FCR and mortality in broiler, tremendous drop in egg production in layers and increase embryo mortality in breeders (Stipkovits and Kempf, 1996; Kleven and Noel, 2008; Ley, 2008). The disease may be transmitted horizontally and vertically and remains in the flock constantly as subclinical form (Bradbury and Jordan, 2003). It has been shown that an association between infection of the oviduct with MS and the eggshell apex abnormalities (EAA) characterized by a

${ }^{*}$ Corresponding author. E-mail: pkhoshkho@kiau.ac.ir. Tel: +98 2614460465 . Fax: +98 2614482648 roughened shell surface, shell thinning, increased translucency, cracks and breaks (Feberwee et al., 2009). In the last years, there have been reported a high prevalence of avian mycoplasmosis and increasing of MS infection, possibly due to the growth of large flocks within small geographically areas, under inadequately biosafety conditions (Avakian and Kleven, 1990; Keleven and Noel, 2008). This aspect may lead to the need of reevaluating the control strategies, introducing surveillance programs and vaccination which is one of the effective approaches to control and prevention of mycoplasmosis. In order to define the necessity of vaccination, the rate of contamination to this pathogen should be determined. Among serological tests, the serum plate agglutination (SPA) test is very simple, rapid, and sensitive and can be used for the detection of MG \& MS antibodies under field conditions (Kleven, 1998). The present study was carried out to determine the seroprevalence of $M G$ and $M S$ 


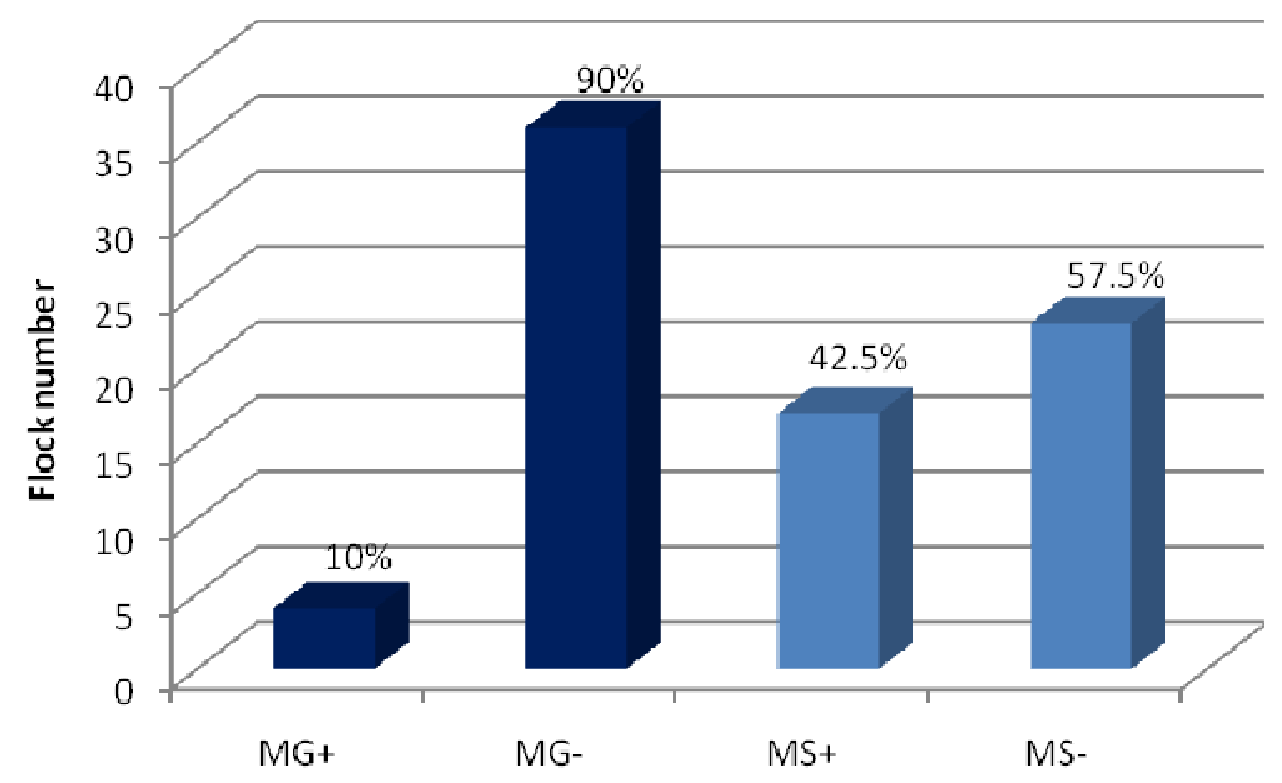

Flock contamination

Figure 1. Seroprevalence of MG and MS on the commercial layer flocks in the Center north of Iran.

infection in the chickens of selected model commercial layer farms of the Centernorth of Iran and detect the correlation between positive farms and breeding variables.

\section{MATERIALS AND METHODS}

\section{Sampling}

A total of 2000 serum samples were collected from 40 commercial layer flocks, mostly above 40 weeks old of age (50 serum samples from each flocks), which were randomly selected in the different areas of two important provinces (in view of poultry production) in Centernorth of Iran during January to May 2010.

\section{Data collection}

Some information about qualitative variables (geographical area of flocks, commercial strain of layer type, breeding system, antibiotic consumed during previous three mounts, present of maternal antibodies against $M G$ and $M S$ at one-day-old of age, any vaccination against $M G$ and $M S$ administered in their parent flocks) and quantitative variables (farm capacity, egg production rate, house number, flock age) were gathered from each farms to be calculated for correlation.

\section{Serum plate agglutination (SPA) test}

The SPA test was done with crystal violet stained $M$. gallisepticum antigen (Nobilis ${ }^{\circledR}$ MG Antigen, Intervet International Co., Holland) and $M$. synoviae antigen (Soleil ${ }^{\circledR}-M S$ Antigen, Ceva International Co, France). For this test $25 \mu \mathrm{l}$ of antigen and $25 \mu \mathrm{l}$ of chicken sera were placed side by side with a sampler on a glass plate and mixed properly by stirring with small tooth pick followed by gentle rocking. Results were read within 2 min. In positive cases granules formed slowly which was seen during rocking, but in negative case no such granules formed within two minutes. Positive reactions retested by SPA on 1:8 dilution and those sera which were positive in the first SPA test but showed negative reaction in the second SPA test were considered suspect. The flocks with more than $10 \%$ positive reactions were considered positive serologically based on the suggestion of Kleven and Bradbury, (2008).

\section{Data analysis}

Statistical analysis was done by SPSS soft ware (Version 16) and T-Test for calculation of correlation between MG and MS positive flocks and breeding variables.

\section{RESULTS}

The results showed that 4 of $40(10 \%)$ flocks were MG positive and the rest $(90 \%)$ were negative. About MS, 17 of $40(42.5 \%)$ flocks were positive and 33 of $40(57.5 \%)$ were negative. Sera tested for MG were: 125 of 2000 $(6.25 \%)$ positive, 1821 of $2000(91.05 \%)$ negative and 54 of $2000(2.7 \%)$ suspect. Sera for MS were: 371 of 2000 (18.55\%) positive, 1617 of 2000 (80.85\%) negative and 12 of $2000(0.6 \%)$ suspect (Figures 1 and 2). Statistical analysis was done by SPSS soft ware (version 16) and TTest to calculate the correlation between MG and MS positive flocks and breeding variables. Among qualitative variables, only the strain of layer flock was significant 


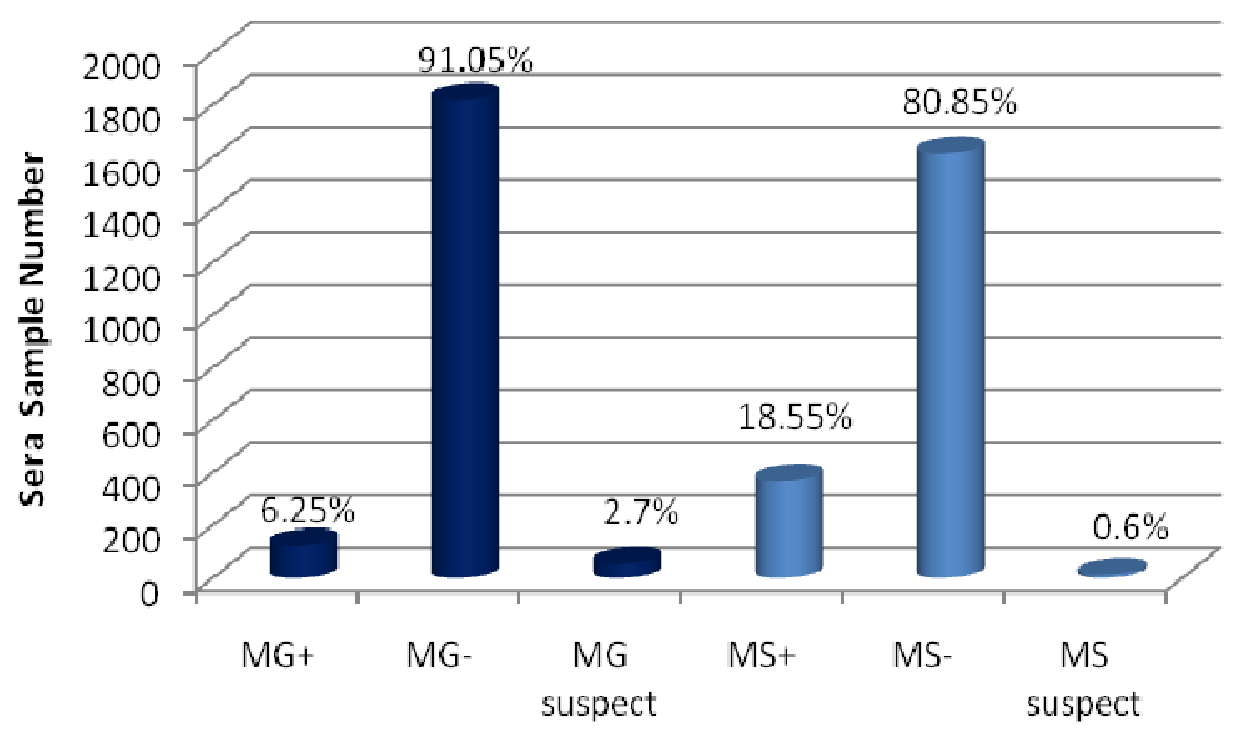

Sera Contamination

Figure 2. SPA reaction against MG \&MS on sera samples from commercial layer flocks in the Centernorth of Iran.

correlation. Rate of MS contamination in the flocks with L.S.L strain, was more than flocks with Hy-Line strain significantly $(\mathrm{P}<0.05)$. Of quantitative variables, two variables of house number and farm capacity were significant. Rate of MS contamination in the farms which had more house and high capacity were higher than the other significantly $(p<0.05)$. Due to low rate of $M G$ positive flocks, correlation between positive flocks and breeding variables was not calculated.

\section{DISCUSSION}

The present study was done in order to determine the seroprevalence of $M$. gallisepticum and $M$. synoviae infections in the commercial layer flocks in the Centernorthern of Iran by serum plate agglutination (SPA) test as a screening test. According to the results, the seroprevalence of MG in the studied areas was low; only 4 of $40(10 \%)$ flocks were positive, whereas seroprevalence of MS was high (42.5\%) and there were a significant correlation between MS positive flocks and flock strain, farm capacity, house number of farm. Therefore, the commercial layer flocks which were L.S.L strain (compared to Hy-Line), had more capacity and more houses seemed to be more sensitive to MS infection. It seems that intensive nature of poultry farming provides opportunity for recycling of the pathogens due to population density. Because of low rate of MG positive farms, correlation between positive farms and breeding variables was not calculated. Seroprevalence of $M G$ in the different areas of Bangladesh by SPA test reported
$58.9 \%$ (Sarkar et al., 2005) in breeder poultry farms and $49.50 \%$ in broiler and $66.50 \%$ in layer (Barua et al., 2006), with the highest and lowest prevalences in winter and summer seasons respectively. These findings were in close agreement with the previous results reported by Alam et al. (2003) in Bangladesh, Kelly et al. (1994) in Zimbabwe, Shah-Majid (1996) in Malaysia, Pandey and Hasegawa (1998) in Zambia, Mushi et al. (1999) in Botswana and Chakraborty et al. (2001) in India who reported the seroprevalence of mycoplasmosis are higher in winter and for this reason we collected the sera mostly in cold season.

In our study, seroprevalence of MS was more than MG. It seems that MS is widely spread (Kleven and Noel, 2008). Buim et al. (2009) showed that mycoplasmas was isolated from $72.7 \%$ of poultry farms in Brazil by multiplex PCR with predominance of MS. Suzuki et al. (2009) reported seroprevalence of MS was $53 \%$ by Elisa test with the high rate of MS infection. In the Germany, $84 \%$ of commercial layer flocks during laying period were positive for mycoplasmas in PCR test, while $75 \%$ turned out positive for MS and all were negative for MG (Köhn et al., 2009). Feberwee et al. (2008) showed that the seroprevalence of MS in commercial poultry by SPA was $73 \%$ in Dutch. Kapetanov et al. (2010) reported that the overall seroprevalence of the MG and MS of the flocks in Serbia was 9.01 and $47.49 \%$ in 2000 and was 11.59 and $22.17 \%$ in 2009 by SPA and Elisa tests respectively and concluded that seroprevalence of MS was decreased, versus the MG increased.

The age of flock that we chose, was over 40-week-old. In the epidemiological study of MG and MS in Romania 
by ELISA test, Botus et al. (2008) showed that high seroprevailence $(80 \%)$ of $M G$ and $M S$ was detected from poultry older than 36 weeks. We use SPA test based on the suggestion of Kleven and Bradbury, (2008) SPA test is quick, relatively inexpensive and sensitive and can be widely used as an initial screening test for flock monitoring and serodiagnosis. Comparison with the other serological tests, SPA is more sensitive than Elisa and $\mathrm{HI}$, but less specific than them (Ley, 2008). However, the SPA test is prone to false positive results and nonspecific reactions (Avakian et al., 1993; Czifra et al., 1993; Abdelmoumen and Roy, 1995; Osman et al., 2009). Certain nonspecific SPA reactions may be reduced by diluting the serum (Ross et al., 1990), so in the present study positive reactions retested by SPA on 1:8 dilution. Comparison of culture, PCR, and different serologic tests (SPA, $\mathrm{HI}$ and ELISA) for detection of MG and MS infections, Feberwee et al. (2005) showed that it is not advisable to rely completely on only one test (system) and Ewing et al. (1996) suggested that PCR should be considered as confirmatory test for SPA and ELISA for MG and MS infections.

\section{Conclusion}

It is concluded that the seroprevalence of MS infection in the commercial layer farms of the Centernorth of Iran, in contrast to $M G$ infection, is high. However, the use of live MS and MG vaccines as a prevention strategy in commercial layer flocks needs more studies, and molecular identification should be used for the completion of these findings.

\section{REFERENCES}

Abdelmoumen B, Roy RS (1995). Antigenic relatedness between seven avian Mycoplasma species as revealed by western blot analysis. Avian Dis., 39: 250-262.

Alam J, Koike I, Giasuddin M, Rahman M (2003). Seroprevalence of poultry diseases in native chickens in Bangladesh. 9th BSVER Annual Scientific Conference. BSVER Publication no. 24, pp 26.

Avakian AP, Kleven SH (1990). The humoral immune response of chickens to Mycoplasma gallisepticum and Mycoplasma synoviae studied by immunoblotting. Vet. Microbiol., 24: 155-170.

Avakian AP, Kleven SH (1993). Method of detecting Mycoplasma infection in poultry and compositions therefore. Document type and number: United States Patent 5196514. University of Georgia Research Foundation, Athens, Georgia.

Barua SR, Prodhan AM, Islam S, Chawdhury S (2006). Study on Mycoplasma gallisepticum in chicken. Bangladesh J. Vet. Med., 4: 141-142.

Botus D, Popa V, Stratulat GH, Catana N (2008). Epidemiological aspects of avian mycoplasmosis during 2007. Lucrari Scientific Med. Vet., XILI: 536-543.

Bradbury JM, Jordan F (2003). Avian mycoplasmasis in: Jordan F et al (eds), Poultry diseases, Bailliere tindal, London. pp: 47-85.

Buim MR, Mettifogo E, Timenetsky J, Kleven S, Ferreira AJP (2009). Epidemiological survey on Mycoplasma gallisepticum and $M$. synoviae by multiplex PCR in commercial poultry. Pesquisa Veterinaria Brasileira, 29: 552-556.

Chakraborty D, Sadhukahan T, Guha D, Chatarjee A (2001).
Seroprevalence of Mycoplasma gallisepticum in West Bengal. Ind. Vet. J., 78: 855-856.

Czifra G, Tuboly T, Sundquist BG, Stipkovits L (1993). Monoclonal antibodies to $M$. gallisepticum membrane proteins. Avian Dis., 37: 689-696.

Ewing ML, Lauerman LH, Kleven SH, brown MB (1996). Evaluation of diagnostic procedure to detect Mycoplasma synoviae in commercial multiplier-breeder farms and commercial hatcheries in Florida. Avian Dis., 40: 798-806.

Feberwee A, De Vries TS, Landman WJM (2008). Seroprevalence of Mycoplasma synoviae in Dutch commercial poultry farm. Avian Pathol., 37: 629-633.

Feberwee A, De Wit JJ, Landman WJM (2009). Induction of eggshell apex abnormalities by Mycoplasma synoviae: field and experimental studies. Avian Pathol., 38: 77-85

Feberwee A, Mekkes DR, De Wit JJ, Hartman, EG, Pijpers A (2005). Comparison of culture, PCR, and different serologic tests for detection of Mycoplasma gallisepticum and Mycoplasma synoviae Infections. AvianDis., 49: 260-268.

Kapetanov M, Orlic D, Potkonjak D, Velhner M (2010). Mycoplasma in poultry flocks in the year 2009 compare to the year 2000 and significance of the control measures in Serbia. Lucrari scientific Med. Vet. XLIII: 249-253.

Kelly PJ, Chitauro D, Rhode C, Rukwava J, Majok A, Davelar F, Mason PR (1994). Diseases and management of backyard chicken flocks in chiturgwiza. Zimbabwe. Avian Dis., 38: 626-629.

Kleven SH (1998). Mycoplasmosis. In: Swayne DE et al (eds) A Laboratory manual for the isolation and identification of avian pathogens. American Association of Avian Pathologists, USA, pp. 7480.

*Kleven SH, Bradbury JM (2008). Avian mycoplasmosis (mycoplasma gallisepticum, M. synoviae). In: OIE Standards Commission eds. OIE manual of diagnostic tests and vaccines for terrestrial animals (mammals, birds and bees). Office International des Epizooties. Paris. Pp. 482-496.

Kleven SH, Noel NF (2008). Mycoplasma synoviae infection. In: Saif $\mathrm{YM}$ et al (eds) Diseases of poultry, Ames, lowa State University Press. USA, pp. 845-856.

Köhn S, Spergse J, Ahlers C, Voss M, Bartels T, Rosengarten R, Krautwald-Junghanns ME (2009). Prevalence of Mycoplasmas in commercial layer flocks during laying period. Klinikfür Vögelund Reptilien der Universität Leipzig. Berl Munch Tierarztl Wochenschr 122: 186-92.

Ley DH (2008). Mycoplasma gallisepticum infection. In: Saif YM et al (eds) Diseases of poultry, Ames, lowa State University Press. USA pp. 805-833.

Mushi EZ, Binta MG, Chabo RG, Mathaio M, Ndebele RT (1999). Detection of Mycoplasma gallisepticum and $M$. synoviae antibodies in the sera of indigenous chickens by Rapid Plate agglutination test at Mnopane, Gabornone, Botswana, Onderstepeort. J. Vet. Res., 66: 333- 334.

Osman KM, Aly MM, Amin ZMS (2009). Mycoplasma gallisepticum: an emerging challenging to the poultry industry in Egypt. Revue Scientifiqueet Technique (International Office of Epizootics), 28: 1015-1023.

Pandey GS, Hasegawa M (1998). Serological survey of Mycoplasma Gallisepticum and Mycoplasma synoviae infection in chickens Zambia. Bull. Anim. Health Prod. Afr., 46: 113-117.

Sarkar SK, Rahman MB, Khan MFR (2005). Sero-Prevalence of Mycoplasma gallisepticum infection of chickens in model breeder poultry farms of bangladesh. Int. J. Poult. Sci., 4: 32-35.

Shah-Majid M (1996). Detection of Mycoplasma gallisepticum antibodies in sera of village chickens by the enzyme linked Immuno sorbent assay. Trop. Anim. Health Prod., 28: 181-182.

Stipkovits L, Kempf I (1996). Mycoplasmosis in poultry. Revue Scientifiqueet Technique (International Office of Epizootics), 15: 1495-1525.

Suzuki K, Origlia J, Alvarez F, Faccioli M, Silva M, Caballero J, Nunrez L, Castro L (2009). Relative risk estimation for Mycoplasma synoviae in backyard chickens in Paraguay. Int. J. Poult. Sci., 8: 842-847. 